University of South Carolina

Scholar Commons

10-14-2009

\title{
An Intertidal Sea Star Adjusts Thermal Inertia to Avoid Extreme Body Temperatures
}

Sylvain Pincebourde

University of South Carolina - Columbia

Eric Sanford

University of California - Davis

Brian Helmuth

University of South Carolina - Columbia, helmuth@sc.edu

Follow this and additional works at: https://scholarcommons.sc.edu/biol_facpub

Part of the Biology Commons

\section{Publication Info}

The American Naturalist, ed. Craig W. Benkman, Volume 174, Issue 6, 2009, pages 890-897.

(c) The American Naturalist 2009, The University of Chicago Press.

This Article is brought to you by the Biological Sciences, Department of at Scholar Commons. It has been accepted for inclusion in Faculty Publications by an authorized administrator of Scholar Commons. For more information, please contact digres@mailbox.sc.edu. 


\title{
Natural History Note
}

\author{
An Intertidal Sea Star Adjusts Thermal Inertia to Avoid \\ Extreme Body Temperatures
}

\author{
Sylvain Pincebourde, ${ }^{1, *}$ Eric Sanford, ${ }^{2}$ and Brian Helmuth ${ }^{1}$
}

1. Department of Biological Sciences, University of South Carolina, Columbia, South Carolina 29208; 2. Department of Evolution and Ecology, University of California, Davis, California 95616; and Bodega Marine Laboratory, Bodega Bay, California 94923

Submitted February 13, 2009; Accepted August 5, 2009; Electronically published October 14, 2009

Online enhancements: appendixes.

ABSTRACT: The body temperature of ectotherms is influenced by the interaction of abiotic conditions, morphology, and behavior. Although organisms living in different thermal habitats may exhibit morphological plasticity or move from unfavorable locations, there are few examples of animals adjusting their thermal properties in response to short-term changes in local conditions. Here, we show that the intertidal sea star Pisaster ochraceus modulates its thermal inertia in response to prior thermal exposure. After exposure to high body temperature at low tide, sea stars increase the amount of colderthan-air fluid in their coelomic cavity when submerged during high tide, resulting in a lower body temperature during the subsequent low tide. Moreover, this buffering capacity is more effective when seawater is cold during the previous high tide. This ability to modify the volume of coelomic fluid provides sea stars with a novel thermoregulatory "backup" when faced with prolonged exposure to elevated aerial temperatures.

Keywords: body temperature, intertidal ecology, Pisaster ochraceus, thermal inertia, thermoregulation, water temperature.

\section{Introduction}

The performance and fitness of ectotherms are profoundly influenced by body temperature. Body temperature is determined by the biophysical processes underlying heat exchange between an organism's body and its environment (Gates 1980). Indeed, the morphological and physiological properties of an ectotherm act as a biological filter of microclimatic conditions and determine, in part, the resulting body temperature (Huey 1991). Consequently, the body temperature of an ectotherm generally deviates from air temperature (Casey 1992; Helmuth 1998), and body

\footnotetext{
* Corresponding author. Present address: Institut de Recherche sur la Biologie de l'Insecte, Centre National de la Recherche Scientifique, Unité Mixte de Recherche 6035, Université François Rabelais, Faculté des Sciences et Techniques, 37200 Tours, France; e-mail: sylvain.pincebourde@univ-tours.fr.

Am. Nat. 2009. Vol. 174. pp. 890-897. () 2009 by The University of Chicago. 0003-0147/2009/17406-51076S15.00. All rights reserved.

DOI: $10.1086 / 648065$
}

temperatures often differ among species, even under identical climatic conditions (Helmuth 2002; Broitman et al. 2009). Moreover, organisms that can modify or adjust these thermal properties in response to fluctuations in the abiotic environment may escape from unfavorable conditions to remain in the range of body temperatures that are optimal for performance.

Long-term adjustments of organismal thermal properties can occur through adaptive phenotypic plasticity or adaptation via selection. The most striking example of such an adjustment is variation in body coloration in response to different thermal environments, as seen in the adaptive role of melanin in thermoregulation by insects (Watt 1968; Kingsolver and Huey 1998; Nice and Fordyce 2006) and lizards (Clusella-Trullas et al. 2008) and in selection for shell color polymorphism in snails (Etter 1988). Other examples include phenotypic plasticity in traits such as body size and wing size in flies under varying thermal regimes (Crill et al. 1996). In contrast, little is known regarding adjustments of organismal thermal properties that might buffer against environmental fluctuations occurring over short timescales (i.e., minutes to days). At this temporal scale, most studies have focused on behavioral thermoregulation strategies, such as microhabitat selection or changing posture relative to solar position or a warm substrate (May 1979; Garrity 1984; Samietz et al. 2005). Evapotranspiration is also a well-known mechanism that lowers the body temperature of ectotherms during a short period (Prange 1996; DeNardo et al. 2004). However, other potential physiological mechanisms allowing thermoregulation without relocation to another microhabitat have been generally overlooked.

In ectotherms, body temperature change depends significantly on the thermal inertia of the organism. Thermal inertia can be defined physically by the time constant of heating or cooling that describes the time lag for an organism to reach equilibrium body temperature after a 
change in environmental conditions (Monteith and Unsworth 2008). Thermal inertia is influenced by the mass, specific heat capacity, and thermal conductivity of the organism. Animals and plants with a larger mass, or those composed of tissues with a high specific heat capacity, take much longer to heat or cool compared to less massive organisms or those whose tissues have a low specific heat capacity. For example, although large intertidal mussels in a constant environment may ultimately reach higher body temperature than small mussels, they are buffered against rapid environmental changes because they have a higher thermal inertia (Helmuth 1998). A higher thermal inertia, therefore, appears to be an advantage in an environment with large and rapid temperature fluctuations. Nevertheless, to our knowledge, the only examples of organisms actively adjusting thermal inertia to escape from shortterm occurrence of extreme body temperatures are found in reptiles. Some turtles can adjust their internal circulation to minimize the heating rate (i.e., augment the time constant) so that they maximize the time available for foraging when exposed to the sun and heat stress (Bakken and Gates 1975; Seebacher and Franklin 2005). Here, we tested the ability of an intertidal sea star to lower its body temperature by adjusting its thermal inertia in response to unfavorable conditions.

Large and rapid temperature fluctuations are common in intertidal ecosystems, where organisms are alternatively exposed to marine and terrestrial environments during tidal cycles. The physiological ecology of intertidal organisms is influenced strongly by water temperature during high tide as well as body temperature while exposed to air during low tide (Sanford 1999, 2002; Helmuth et al. 2006; Pincebourde et al. 2008). Little is known, however, about the physical interplay between underwater and aerial body temperatures in intertidal organisms (but see modeling results in Wethey 2002 and Gilman et al. 2006).

We investigated the sensitivity of aerial body temperature $\left(T_{\text {body }}\right)$ at low tide to changes in water temperature $\left(T_{\mathrm{w}}\right)$ experienced at high tide in the ochre sea star Pisaster ochraceus, a keystone predator in rocky intertidal communities along the Pacific Coast of North America (Paine 1966). Given the ecological importance of this predator, the thermal ecology of P. ochraceus may have consequences for the dynamics and structure of intertidal communities (Sanford 1999; Burnaford and Vasquez 2008; Pincebourde et al. 2008; Robles et al. 2009). Sea stars have a spacious coelomic cavity that extends into each arm and can hold substantial fluid that is composed largely of seawater (Ferguson 1992). On average, coelomic fluid constitutes 30\% of the wet body mass of $P$. ochraceus (Pincebourde et al. 2008; S. Pincebourde, unpublished data). We hypothesized that this coelomic fluid may buffer, at least partially, rapid increases in a sea star's $T_{\text {bod }}$ during low tide by effectively increasing thermal inertia.

Material and Methods

Study Location and Temperature Patterns

Pisaster ochraceus was collected in May 2007 from a single site near the Bodega Marine Reserve in Bodega Bay, California, where this sea star is common in the low- and midintertidal zones. Daily maximal $T_{\text {body }}$ for this sea star ranges from about $10^{\circ}$ to $28^{\circ} \mathrm{C}$ throughout spring and summer, and extreme $T_{\text {body }}\left(28^{\circ} \mathrm{C}\right)$ can be reached any time during this period (Pincebourde et al. 2008). Therefore, sea stars used in this study likely experienced such extremes before collection. At this location, water temperature typically varies between $10^{\circ}$ and $16^{\circ} \mathrm{C}$ in spring and summer (Bodega Ocean Observing Node; http://bmlsc .ucdavis.edu/boon/). All laboratory trials were conducted at the Bodega Marine Laboratory.

\section{The Experimental Setup}

The experimental setup enabled us to fully control both $T_{w}$ during high tide and $T_{\text {body }}$ of sea stars during low tide (fig. Al in the online edition of the American Naturalist). A tidal cycle was simulated in 27 identical aquariums ( 75 L) by alternating periods with aquariums full and nearly empty of water. The low tide was set $50 \mathrm{~min}$ later on each subsequent day to mimic the natural tidal rhythm. Sea stars were aerially exposed daily for $6 \mathrm{~h}$, which corresponds to a realistic emersion period for low- to midintertidal organisms in this region. No food was provided to the sea stars.

To place all animals in a similar physiological condition, sea stars were acclimated in the aquariums for 8 days before the start of each experiment at $T_{\mathrm{w}}$ of $13^{\circ} \mathrm{C}$ and $T_{\text {bodv }}$ of $13^{\circ}-15^{\circ} \mathrm{C}$ during daily low tides. In all experiments, an electronic scale was used to record wet-mass changes of animals (to the nearest $0.1 \mathrm{~g}$ ), as an indirect measurement of variation in fluid volume. Controls further confirmed that any loss in dry body mass over a period of about 15 days without food was negligible compared to the variations in wet body mass that we observed (see "Results"). A separate set of sea stars was used for each of the two experiments. Wet body mass (mean $\pm \mathrm{SD}$ ) of sea stars was $169.8 \pm 32.1 \mathrm{~g}$ and $197.3 \pm 35.3 \mathrm{~g}$ at the start of experiments 1 and 2 , respectively. 


\section{Experiment 1: Relationships among $\mathrm{T}_{w,} \mathrm{~T}_{\text {body }}$ and Wet Body Mass}

This experiment tested two hypotheses: first, that exposure to cooler $T_{\mathrm{w}}$ at high tide buffers against $T_{\text {body }}$ increases during the subsequent low tide and, second, that sea stars experiencing warmer $T_{\text {bodv }}$ during low tide increase the volume of coelomic fluid during the subsequent high tide, resulting in increased thermal inertia. Twenty-four aquariums, each containing a single sea star, were assigned to one of three $T_{w}$ treatments: $10^{\circ}, 13^{\circ}$, and $16^{\circ} \mathrm{C}(n=8$ aquariums per treatment). Each aquarium was an independent replicate (water was not recirculated among replicates) and was equipped with its own heat lamp (app. A in the online edition of the American Naturalist). Both the height and the angle of heat lamps relative to animal bodies were exactly the same in all aquariums for each low tide. This fixed setting was determined as the heat lamp position needed so that sea stars in the $T_{w}$ treatment $16^{\circ} \mathrm{C}$ would reach $T_{\text {body }}$ of about $27^{\circ} \mathrm{C}$ during the first low tide $\left(27^{\circ} \mathrm{C}\right.$ is an extreme $T_{\text {body }}$ found regularly at the study site and is well below the lethal body temperature threshold of $35^{\circ} \mathrm{C}$; Pincebourde et al. 2008). The $T_{\text {body }}$ was measured every $30 \mathrm{~min}$, and here we report the maximal values that were obtained by the end of the 6 -h low-tide period. The "body temperature excess" of sea stars was calculated as an indicator of $T_{\text {body }}$ sensitivity to aerial conditions during low tide. This metric was defined as the difference between $T_{\text {body }}$ and ambient temperature in the aquariums, such that a positive body temperature excess indicated that $T_{\text {body }}$ was higher than ambient temperature. In addition to aquariums in the three treatments, a single aquarium containing four sea stars was assigned to each $T_{\mathrm{w}}\left(10^{\circ}, 13^{\circ}\right.$, and $\left.16^{\circ} \mathrm{C}\right)$. In these control aquariums, individuals were left underwater all the time (i.e., no low tide) to test whether the variation in wet body mass was caused directly by $T_{\mathrm{w}}$ in the absence of any aerial exposure. This experiment lasted 6 days. Wet body mass of all sea stars was measured at the end of each 18-h period of submergence (i.e., right before each low tide). Wet body mass was also measured at both the start and the end of the last low tide, to estimate the amount of water lost through evapotranspiration during a single period of aerial exposure.

\section{Experiment 2: Effect of Aerial Exposure on Wet Body Mass}

This second experiment manipulated $T_{\text {body }}$ directly, to provide an independent test of the hypothesis that sea stars experiencing warmer $T_{\text {body }}$ during low tide increase the volume of coelomic fluid during the subsequent high tide. In addition, this experiment tested the hypothesis that coelomic fluid volume returns to initial levels when sea stars are no longer exposed to warm aerial conditions.
Eighteen aquariums, each containing a single sea star, were assigned to one of two $T_{\text {body }}$ treatments: $16^{\circ}$ and $26^{\circ} \mathrm{C}$ ( $n=9$ aquariums per treatment). The $T_{w}$ was $10^{\circ} \mathrm{C}$ in all aquariums. These temperatures were applied daily for 6 days. Then, all sea stars were held at $T_{\text {body }} 16^{\circ} \mathrm{C}$ during low tides for 3 days to test whether wet body mass changed after the cessation of warm aerial conditions. A single aquarium containing five sea stars left underwater continuously at $10^{\circ} \mathrm{C}$ served as a control. Wet body mass of all sea stars was measured immediately before each low tide.

\section{Statistical Analysis}

Response variables ( $T_{\text {body }}$ and wet mass) were recorded in the same sea stars on sequential days, and thus repeatedmeasures analyses were used to account for the correlation among dates within individuals. In general, repeatedmeasures data can be analyzed using either a univariate (repeated-measures ANOVA, RM-ANOVA) or a multivariate (MANOVA) approach (von Ende 1993; Zar 1999, p. 259). Although more powerful, the use of RM-ANOVA requires that the data exhibit sphericity (i.e., homogeneity in the variance of the differences between all possible pairs of repeated measures). When this condition is not satisfied, $F$ statistics for the within-subject factor (i.e., time) are inflated, and it is necessary to either alter the degrees of freedom in the univariate analysis by using the HuynhFeldt adjustment (thereby generating a more conservative $P$ value for a given $F$ ratio) or use the multivariate approach that is insensitive to the sphericity assumption (von Ende 1993; Zar 1999). In the latter case, the response variable for each level of the within-subject factor (e.g., wet mass recorded on each date) is treated as a separate dependent variable within the MANOVA model (von Ende 1993).

Four separate RM-ANOVAs were used to examine three response variables in experiment 1 ( $T_{\text {body }}$, body temperature excess, and cumulative change in wet mass) and one response in experiment 2 (cumulative change in wet mass). In each case, temperature treatment was the betweensubjects factor $\left(T_{w}\right.$ in experiment 1 and $T_{\text {budy }}$ in experiment 2 ), individual sea stars were the subjects within each treatment, and time (consecutive sampling days) was the within-subject factor. The controls with sea stars submerged continuously were not included in these analyses. Multiple sea stars were maintained in the same aquarium because of limitations in the number of aquariums available, and thus these individuals cannot be treated as independent replicates. Therefore, mean values from unreplicated control aquariums are presented graphically for reference only. For each RM-ANOVA, the assumption of sphericity was tested with Mauchly's test (von Ende 1993). The assumption of sphericity was satisfied for analyses of 
$T_{\text {body }}$ and body temperature excess but not for analyses of cumulative wet-mass change. In these latter cases, results of the RM-ANOVA are presented with more conservative Huynh-Feldt-adjusted $P$ values (along with MANOVA results for comparison).

In experiment 1 , Pearson's correlation was also used to estimate the strength of the relationship between body temperature excess and wet body mass change. Within each time period of experiment 2 , separate $t$-tests were used to test for differences in response variables between the two treatments. In these $t$-tests, significance was evaluated using a Bonferroni-adjusted probability of Type I error to account for multiple comparisons across the nine dates $(\alpha=0.05 / 10=0.005)$. All statistical analyses were done using SYSTAT 10 (SYSTAT Software, Richmond, CA).

\section{Results \\ Experiment 1: Relationship among $\mathrm{T}_{w}, \mathrm{~T}_{\text {bodys }}$ and Wet Body Mass}

Consistent with our hypothesis, exposure to cooler water temperature $\left(T_{\mathrm{w}}\right)$ during high tide led to lower $T_{\text {body }}$ during the subsequent low tide (fig. $1 A$; RM-ANOVA, $T_{\mathrm{w}}$ treatment: $F_{2,21}=188.74, P<.0001$; app. $\mathrm{B}$ in the online edition of the American Naturalist). This occurred despite the fact that sea stars experienced exactly the same daily aerial microclimatic conditions in all aquariums.

Ambient temperature within aquariums at low tide varied slightly throughout the experimental period because of the influence of external weather on room temperature (fig. 1A). We therefore calculated the difference between $T_{\text {body }}$ and ambient temperature within aquariums to estimate the temporal dynamic of the body temperature excess (i.e., the degrees by which body temperature exceeded ambient air temperature). Body temperature excess differed among treatments and was greatest in sea stars that experienced high $T_{\mathrm{w}}$ (fig. $1 B$; RM-ANOVA, $T_{\mathrm{w}}$ treatment: $\left.F_{2,21}=188.74, P<.0001\right)$. However, body temperature excess decreased over the 5 days of low-tide exposure, and this decline was most pronounced in the $16^{\circ} \mathrm{C} T_{w}$ treatment (fig. $1 B$; RM-ANOVA, time $\times T_{\mathrm{w}}$ treatment: $F_{8,84}=15.66$, $P<.0001$ ). Body temperature excess during the last low tide was, on average, $3.5^{\circ}, 1.7^{\circ}$, and $0.9^{\circ} \mathrm{C}$ lower than during the first low tide in $T_{w}$ treatments at $16^{\circ}, 13^{\circ}$, and $10^{\circ} \mathrm{C}$, respectively. This reduction suggests that sea stars employed mechanisms to buffer body temperature excess during warm aerial conditions.

The increase in wet body mass measured at the end of each high tide was greater in sea stars held in the warmer $T_{\mathrm{w}}$ treatments (fig. $1 C$; RM-ANOVA, $T_{\mathrm{w}}$ treatment: $F_{2,21}=$ $21.09, P<.0001)$. Moreover, the wet body mass of sea stars experiencing warmer $T_{w}$ increased over the course of the
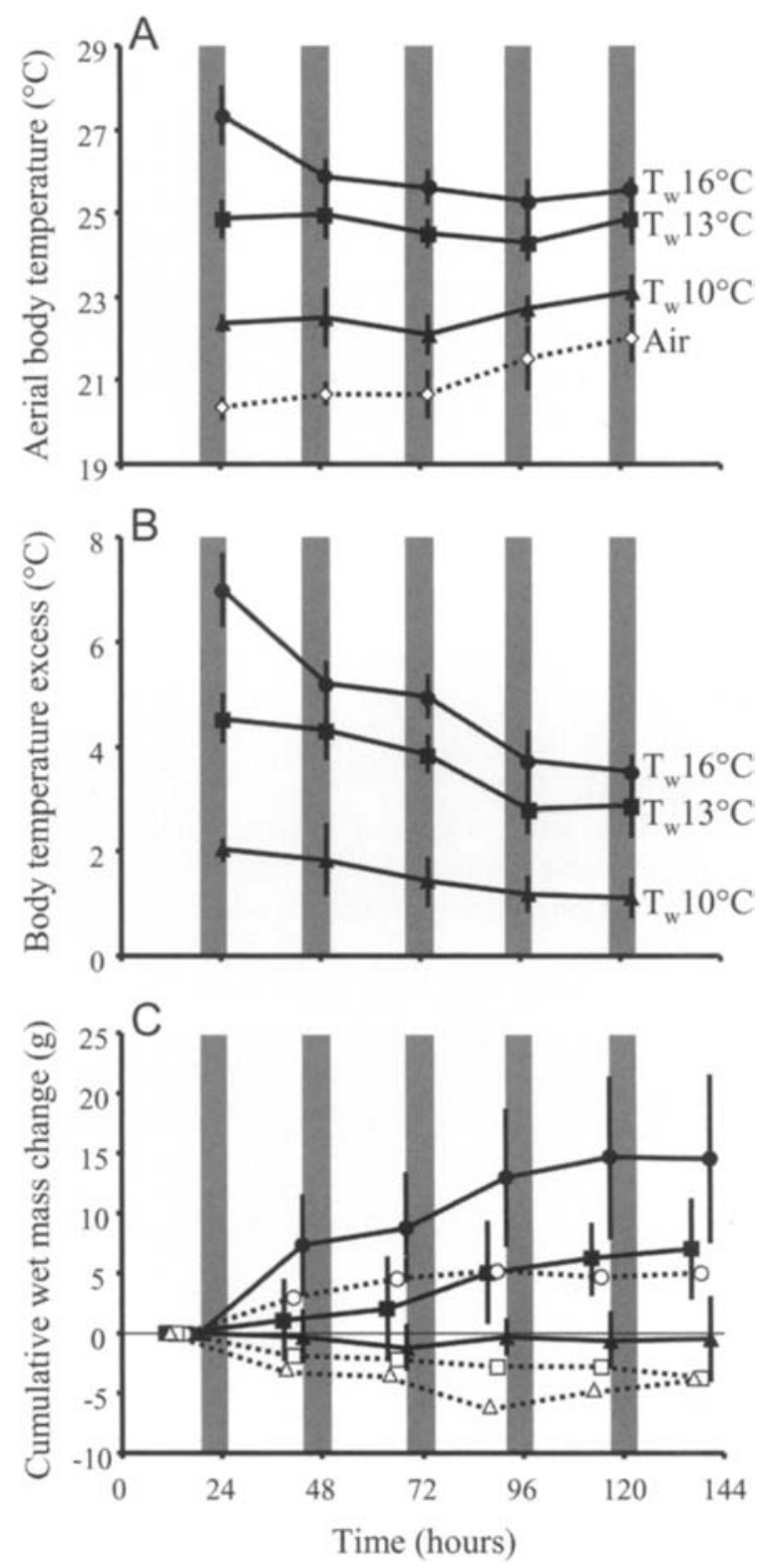

Figure 1: Relationship among water temperature $\left(T_{w}\right)$, aerial body temperature $\left(T_{\text {body }}\right)$, and cumulative wet body mass change of sea stars. Sea stars were exposed to one of three $T_{w}$ treatments at high tide, and aerial conditions were identical among all tanks during five low-tide periods (bars). A, Mean $T_{\text {body }}( \pm \mathrm{SD})$ of sea stars at the end of each low tide is given for $T_{w}$ treatments at $16^{\circ}$ (circles), $13^{\circ}$ (squares), and $10^{\circ} \mathrm{C}$ (triangles, $n=8$ aquariums per treatment). Mean ambient temperature ( \pm SD) in aquariums during low tide is also shown (diamonds). $B$, Mean body temperature excess ( $\pm S D$; i.e., aerial body temperature minus ambient aquarium temperature) in each $T_{w}$ treatment. $C$, Mean cumulative change in wet body mass of sea stars $( \pm S D)$ through time in each $T_{w}$ treatment. Mass measurements were all made at the end of each high tide (symbols are slightly shifted for clarity). Individuals were left underwater continuously in the controls at $T_{\mathrm{w}} 16^{\circ}$ (open circles), $13^{\circ}$ (open squares), and $10^{\circ} \mathrm{C}$ (open triangles, $n=1$ aquarium per temperature). 
experiment (fig. $1 C$; RM-ANOVA, time $\times T_{\mathrm{w}}$ treatment: $F_{8,84}=4.80$, Huynh-Feldt-corrected $P=.0016$ ). Sea stars that were constantly submerged at $T_{\mathrm{w}} 16^{\circ} \mathrm{C}$ (control) also accumulated more coelomic fluid (up to $5 \mathrm{~g}$ on average) than controls held at cooler $T_{\mathrm{w}}$ (fig. 1C). However, sea stars subjected to daily aerial exposure showed a greater increase in wet body mass than those in the respective controls (constantly submerged) at all levels of $T_{w}$. These results indicate that although continuous submergence in warmer seawater $\left(T_{w} 16^{\circ} \mathrm{C}\right)$ led to a slight increase in the volume of coelomic fluid, the increase was substantially greater when exposure to warmer seawater was coupled with daily exposure to warm aerial conditions. Responses associated with aerial exposure were probably driven by temperature at low tide rather than desiccation because sea stars lost on average only $8.2 \pm 3.4 \mathrm{~g}$ (i.e., $5 \% \pm$ $1.8 \%$ of initial wet body mass) during the last low tide of the experiment (mean $\pm \mathrm{SD}: 7.3 \pm 2.2,7.8 \pm 3.4$, and $9.6 \pm 4.2 \mathrm{~g}$ in the $T_{\mathrm{w}}$ treatments at $10^{\circ}, 13^{\circ}$, and $16^{\circ} \mathrm{C}$, respectively).

Body temperature excess was closely correlated with cumulative wet body mass change in the $16^{\circ} \mathrm{C} T_{w}$ treatment (Pearson's coefficient $=-0.72, P<.001, r=0.72, n=$ 40; app. $C$ in the online edition of the American Naturalist). The correlation was also significant, although weaker, at $T_{\mathrm{w}} 13^{\circ} \mathrm{C}$ (Pearson's coefficient $=-0.50, P=$ $.001, r=0.5, n=40)$, but it was not significant at $T_{\mathrm{w}}$ $10^{\circ} \mathrm{C}(P=.43)$.

\section{Experiment 2: Effect of Aerial Exposure on Wet Body Mass}

Sea stars experiencing warmer $T_{\text {body }}\left(26^{\circ}\right.$ vs. $\left.16^{\circ} \mathrm{C}\right)$ exhibited a greater increase in wet body mass, further supporting our hypothesis (fig. 2; RM-ANOVA, $T_{\text {body }}$ treatment: $\left.F_{1,16}=35.36, P<.0001\right)$. Wet body mass varied through time, but the nature of these changes depended on the treatment (RM-ANOVA, time $\times T_{\text {body }}$ treatment: $F_{8,128}=$ 8.31, Huynh-Feldt-corrected $P=.0002$ ). Comparisons within each time period indicated that the cumulative wetmass change in sea stars that experienced $T_{\text {body }}$ of $26^{\circ} \mathrm{C}$ for six consecutive low tides was greater than in the $16^{\circ} \mathrm{C} T_{\text {body }}$ treatment for all dates except days 0,1 , and 9 ( $t$-tests for each day; Bonferroni-adjusted $P<.005$ ). These results indicated that sea stars significantly increased the volume of their coelomic fluid after exposure to warm aerial conditions during low tides and that body mass subsequently decreased to its initial level about 3 days after the end of the exposure period. The mean maximal water uptake, obtained after 5 days of exposure, was about $15 \mathrm{~g}$ (fig. 2).

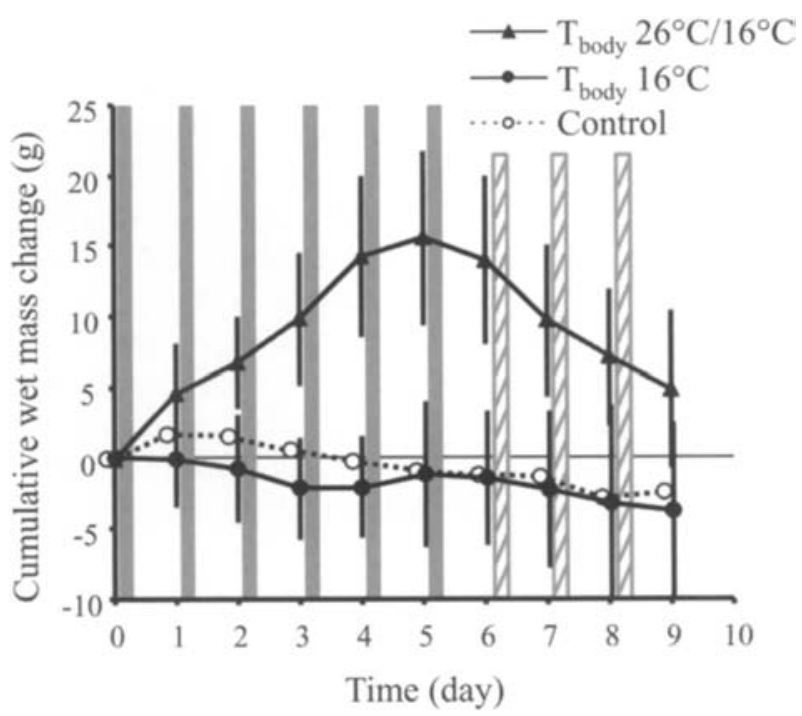

Figure 2: Mean cumulative change in wet body mass $( \pm S D$ ) of sea stars held on a tidal cycle (high-tide water temperature $\left[T_{w}\right]$ of $10^{\circ} \mathrm{C}$ for all aquariums) with aerial body temperature of $26^{\circ} \mathrm{C}$ for six low tides (then $16^{\circ} \mathrm{C}$ for three low tides) versus $16^{\circ} \mathrm{C}$ during all low tides ( $n=9$ aquariums per treatment). The control corresponds to sea stars left underwater $\left(T_{w} 10^{\circ} \mathrm{C}\right)$ continuously $(n=1$ aquarium). Filled bars indicate the lowtide periods with aerial body temperature $26^{\circ} \mathrm{C}$ in the high aerial body temperature treatment, while hatched bars denote low tides with aerial body temperature of $16^{\circ} \mathrm{C}$. Data points in the control are shifted slightly from the two treatments for clarity.

\section{Discussion}

Thermal environments are quite heterogeneous in both time and space. Such heterogeneity imposes constraints on organisms because the optimal body temperature range for physiological performance is often relatively narrow (Huey and Kingsolver 1989; Hochachka and Somero 2002). As a result, ectotherms show various thermoregulatory strategies to deal with an environment that fluctuates with a high frequency. Short-term selection of thermally favorable microsites is the best-known mechanism documented in mobile organisms. Large organisms, however, can benefit from their high thermal inertia to avoid reaching high body temperature in a warm environment during a narrow time window. Some reptiles show the ability to exert a cardiovascular control of heat transfer. They decrease heating or cooling rates by altering their cardiac output and the distribution of blood flow in the body, thereby modifying their time constant (Seebacher and Franklin 2005). For instance, cool reptiles entering a warm environment increase their heart rate to accelerate heat convection by blood flow from the periphery to the core of the organism, allowing animals to reach their preferred body temperature faster. 
Our results show that the ability to adjust thermal inertia in response to environmental change is not restricted to reptiles but is also present in an echinoderm Pisaster ochraceus. This sea star species demonstrates a remarkable ability to modulate its thermal inertia through the use of an external element (seawater) within a short-term window (i.e., the duration of a single tide cycle). This novel strategy is effective because sea stars possess a large, internal, fluidfilled cavity (coelom) and are routinely surrounded by seawater that is cooler than air. Whether this response to elevated $T_{\text {body }}$ is seen in other asteroid species or other intertidal echinoderms with a spacious coelom (e.g., sea urchins, sea cucumbers) remains to be determined. Interestingly, however, seasonal variation in coelomic fluid volume has been observed in at least some other sea stars (Pearse 1967; Franz 1986).

Exposure to high $T_{\text {body }}$ activates a mechanism through which $P$. ochraceus accumulates a greater volume of coelomic fluid, resulting in a lower $T_{\text {body }}$ during the next low tide. Pisaster ochraceus thereby exploits its thermal inertia as a means to slow heating during aerial exposure. The physiological mechanism underlying the observed adjustments is not yet known. Sea stars possess a madreporite (an external, perforated plate located on the aboral surface) that opens into a system of canals that extend to the tube feet (Ferguson and Walker 1991). The madreporite also appears to play a role in regulating the volume of coelomic fluid (Ferguson 1992). The mean rate of seawater flow into the madreporite in this study was $2.34 \mu \mathrm{L} \mathrm{g}^{-1} \mathrm{~h}^{-1}$ (as estimated from the maximal mass of water accumulated in a single high tide), which is in agreement with the rates of $2.21-2.60 \mu \mathrm{L} \mathrm{g}^{-1} \mathrm{~h}^{-1}$ reported by Ferguson (1992) in the same species. The madreporite also seems to participate in adjusting the volume of coelomic fluid after rapid fluid loss because of osmotic changes (Ferguson 1992). Pearse (1967) noted seasonal variations in the volume of coelomic fluid in a subtidal sea star in Antarctica and hypothesized that this volume might be controlled by regulation of small, osmotically active organic molecules, as occurs in some sipunculid worms (Gross 1954). Thermal stress is associated with production of metabolites that could induce an increase in osmotic pressure within the organism (Stillman and Somero 1996), although no data are available to address whether similar processes occur in sea stars. Osmotic stress also increases during evapotranspiration when intertidal organisms are exposed to aerial conditions (Fyhn et al. 1972). The increase in water uptake associated with elevated $T_{\text {body }}$ might be a response to high osmotic pressure. Clearly, further investigation is needed to reveal the underlying physiological mechanism.

Intertidal organisms must cope with temperature variations in both marine (high-tide) and terrestrial (lowtide) environments. Sea stars can experience a wide range of $T_{\text {body }}$ during low tide (Pincebourde et al. 2008; Szathmary et al. 2009) as well as significant changes in $T_{w}$ (Sanford 1999). Our results indicate a tight interdependency between aquatic and aerial body temperatures in P. ochraceus. In particular, $T_{w}$ physically influences maximal $T_{\text {bods }}$ by setting temperature at the start of aerial exposure periods. While aerial microclimatic conditions were strictly the same in all aquariums, $T_{\text {body }}$ was about $5^{\circ} \mathrm{C}$ higher at $T_{w} 16^{\circ}$ than at $10^{\circ} \mathrm{C}$ during the first day of exposure in experiment 1 , suggesting that, when $T_{\mathrm{w}}$ increases from $10^{\circ}$ to $16^{\circ} \mathrm{C}$, the body temperature excess equals about $83 \%$ of the $T_{w}$ change. This value is much higher than that for small intertidal invertebrates, such as barnacles $(20 \%$; Wethey 2002) and mussels (45\%; Gilman et al. 2006). In these other invertebrates, $T_{w}$ sets $T_{\text {body }}$ at the beginning of low tide, and $T_{\text {body }}$ is also influenced by substrate (rock) temperature, which itself depends on $T_{w}$ because of heat storage in the rock ("thermal memory" sensu Gilman et al. 2006). Pisaster ochraceus is much larger and heavier than a mussel or a barnacle, and it also incorporates much more seawater in its coelomic cavity than a mussel holds in its mantle cavity (on average, 58 vs. $4 \mathrm{~g}$ of water, respectively; Pincebourde et al. 2008), leading to a relatively higher thermal inertia. This mechanism obviously serves to reduce $T_{\text {body }}$ only if $T_{w}$ is lower than $T_{\text {body }}$.

The ability of $P$. ochraceus to increase the volume of its coelomic fluid after exposure to high $T_{\text {body }}$ substantially ameliorates $T_{\text {body }}$ during subsequent low tides. This increase is a direct response to temperature rather than to desiccation (app. D in the online edition of the American Naturalist). An increase in the volume of coelomic fluid probably comes with energetic costs or other trade-offs (e.g., impaired locomotion) because sea star wet body mass returned to its basal value when aerial conditions became moderate again. This cost might be balanced by the benefit of remaining close to prey (mussels) that are more abundant higher on the shore. Indeed, although $P$. ochraceus is quite mobile when submerged, it is completely inactive at low tide (Robles et al. 1995). This species can respond behaviorally to high aerial temperature during the next high tide only, by selecting a cooler resting microhabitat (e.g., tide pools or shaded cracks in the rock) or by moving down in the intertidal zone, where $T_{\text {boul }}$ is lower but where mussels are often not present (Pincebourde et al. 2008; Szathmary et al. 2009). The energetic cost of being relatively far from the mussel bed might, however, have imposed selection for sea stars to develop novel thermoregulatory strategies allowing easier access to prey. This study reinforces previous findings indicating that $P$. ochraceus is quite tolerant of acute exposure (i.e., a few consecutive days of exposure) to elevated aerial temperature, whereas more persistent, chronic exposure has strong negative ef- 
fects on feeding and growth rates (Pincebourde et al. 2008).

Finally, our results highlight the interactive roles of water and aerial temperatures in determining levels of physiological stress experienced by intertidal organisms. The efficiency of the thermoregulatory "backup" of sea stars is context dependent. Thermoregulation in P. ochraceus is more effective after exposure to cold seawater, and the probability of experiencing high aerial body temperatures increases when sea temperature is elevated. When placed in a global change context, these results suggest that a continued increase in ocean temperature may compromise the ability of sea stars to avoid thermal stress during aerial exposure at low tide.

\section{Acknowledgments}

We are grateful to M. Kelly, J. Sones, E. Sui Ling Kuo, D. Worth, and the Aquatic Resources Group staff for their help in collecting sea stars or setting up laboratory experiments. We also thank S. Stancyk for his helpful insights on the results, as well as two anonymous reviewers for their comments that strengthened the manuscript. This research was funded by grants from the National Aeronautics and Space Administration (NNG04GE43G) and the National Oceanic and Atmospheric Administration (NA04NOS4780264) to B.H.; S.P. received support through a Lavoisier fellowship (2006-2007) from the French Ministry of Foreign Affairs, and E.S. received support from National Science Foundation grant OCE-06-22924. This manuscript is contribution 2459 from the Bodega Marine Laboratory, University of California, Davis.

\section{Literature Cited}

Bakken, G. S., and D. M. Gates. 1975. Heat transfer analysis of animals: some implications for field ecology, physiology and evolution. Pages 225-290 in D. M. Gates and R. B. Schmerl, eds. Perspectives of biophysical ecology. Springer, New York.

Broitman, B. R., P. L. Szathmary, K. A. S. Mislan, C. A. Blanchette, and B. Helmuth. 2009. Predator-prey interactions under climate change: the importance of habitat vs. body temperature. Oikos 118:219-224.

Burnaford, J. L., and M. Vasquez. 2008. Solar radiation plays a role in habitat selection by the sea star Pisaster ochraceus. Marine Ecology Progress Series 368:177-187.

Casey, T. M. 1992. Biophysical ecology and heat exchange in insects. American Zoologist 32:225-237.

Clusella-Trullas, S., J. S. Terblanche, T. M. Blackburn, and S. L. Chown. 2008. Testing the thermal melanism hypothesis: a macrophysiological approach. Functional Ecology 22:232-238.

Crill, W. D., R. B. Huey, and G. W. Gilchrist. 1996. Within- and between-generation effects of temperature on the morphology and physiology of Drosophila melanogaster. Evolution 50:1205-1218.

DeNardo, D. F., T. E. Zubal, and T. C. M. Hoffman. 2004. Cloacal evaporative cooling: a previously undescribed means of increasing evaporative water loss at higher temperatures in a desert ectotherm, the Gila monster Heloderma suspectum. Journal of Experimental Biology 204:945-953.

Etter, R. J. 1988. Physiological stress and color polymorphism in the intertidal snail Nucella lapillus. Evolution 42:660-680.

Ferguson, J. C. 1992. The function of the madreporite in body fiuid volume maintenance by an intertidal starfish, Pisaster ochraceus. Biological Bulletin 183:482-489.

Ferguson, J. C., and C. W. Walker. 1991. Cytology and function of the madreporite systems of the starfish Henricia sanguinolenta and Asterias vulgaris. Journal of Morphology 210:1-11.

Franz, D. R. 1986. Seasonal changes in pyloric caecum and gonad indices during the annual reproductive cycle in the seastar Asterias forbesi. Marine Biology 91:553-560.

Fyhn, H. J., J. A. Petersen, and K. Johansen. 1972. Eco-physiological studies of an intertidal crustacean, Pollicipes polymerus (Cirripedia, Lepadomorpha). I. Tolerance to body temperature change, desiccation and osmotic stress. Journal of Experimental Biology 57: 83-102.

Garrity, S. D. 1984. Some adaptations of gastropods to physical stress on a tropical rocky shore. Ecology 65:559-574.

Gates, D. M. 1980. Biophysical ecology. Springer, New York.

Gilman, S. E., D. S. Wethey, and B. Helmuth. 2006. Variation in the sensitivity of organismal body temperature to climate change over local and geographic scales. Proceedings of the National Academy of Sciences of the USA 103:9560-9565.

Gross, W. J. 1954. Osmotic responses in the sipunculid Dendrostomum zostericolum. Journal of Experimental Biology 31:402-423.

Helmuth, B. 1998. Intertidal mussel microclimates: predicting the body temperature of a sessile invertebrate. Ecological Monographs 68:51-74.

- 2002. How do we measure the environment? linking intertidal thermal physiology and ecology through biophysics. Integrative and Comparative Biology 42:837-845.

Helmuth, B., N. Mieszkowska, P. Moore, and S. J. Hawkins. 2006. Living on the edge of two changing worlds: forecasting the responses of rocky intertidal ecosystems to climate change. Annual Review of Ecology, Evolution, and Systematics 37:373-404.

Hochachka, P. W., and G. N. Somero. 2002. Biochemical adaptation: mechanism and process in physiological evolution. Oxford University Press, Oxford.

Huey, R. B. 1991. Physiological consequences of habitat selection. American Naturalist 137(suppl.):S91-S1 15.

Huey, R. B., and J. G. Kingsolver. 1989. Evolution of thermal sensitivity of ectotherm performance. Trends in Ecology \& Evolution 4:131-135.

Kingsolver, J. G., and R. B. Huey. 1998. Evolutionary analyses of morphological and physiological plasticity in thermally variable environments. American Zoologist 38:545-560.

May, M. L. 1979. Insect thermoregulation. Annual Review of Entomology 24:313-349.

Monteith, J. L., and M. H. Unsworth. 2008. Principles of environmental biophysics. 3rd ed. Academic Press, London.

Nice, C. C., and J. A. Fordyce. 2006. How caterpillars avoid overheating: behavioral and phenotypic plasticity of pipevine swallowtail larvae. Oecologia (Berlin) 146:541-548.

Paine, R. T. 1966. Food web complexity and species diversity. Amer ican Naturalist 100:65-76.

Pearse, J. S. 1967. Coelomic water volume control in the Antarctic sea-star Odontaster validus. Nature 216:1118-1119. 
Pincebourde, S., E. Sanford, and B. Helmuth. 2008. Body temperature during low tide alters the feeding performance of a top intertidal predator. Limnology and Oceanography 53:1562-1573.

Prange, H. D. 1996. Evaporative cooling in insects. Journal of Insect Physiology 42:493-499.

Robles, C., R. Sherwood-Stephens, and M. Alvarado. 1995. Responses of a key intertidal predator to varying recruitment of its prey. Ecology 76:565-579.

Robles, C. D., R. A. Desharnais, C. Garza, M. J. Donahue, and C. A. Martinez. 2009. Complex equilibria in the maintenance of boundaries: experiments with mussel beds. Ecology 90:985-995.

Samietz, J., M. A. Salser, and H. Dingle. 2005. Altitudinal variation in behavioural thermoregulation: local adaptation vs. plasticity in California grasshoppers. Journal of Evolutionary Biology 18:10871096.

Sanford, E. 1999. Regulation of keystone predation by small changes in ocean temperature. Science 283:2095-2097.

2002. The feeding, growth, and energetics of two rocky intertidal predators (Pisaster ochraceus and Nucella canaliculata) under water temperatures simulating episodic upwelling. Journal of Experimental Marine Biology and Ecology 273:199-218.

Seebacher, F., and C. E. Franklin. 2005. Physiological mechanisms of thermoregulation in reptiles: a review. Journal of Comparative Physiology B 175:533-541.
Stillman, J. H., and G. N. Somero. 1996. Adaptation to temperature stress and aerial exposure in congeneric species of intertidal porcelain crabs (genus Petrolisthes): correlation of physiology, biochemistry and morphology with vertical distribution. Journal of Experimental Biology 199:1845-1855.

Szathmary, P. L., B. Helmuth, and D. S. Wethey. 2009. Climate change in the rocky intertidal zone: predicting and measuring the body temperature of an intertidal keystone predator. Marine Ecology Progress Series 374:43-56.

von Ende, C. N. 1993. Repeated-measures analysis: growth and other time-dependent measures. Pages 113-137 in S. M. Scheiner and J. Gurevitch, eds. Design and analysis of ecological experiments. Chapman \& Hall, London.

Watt, W. B. 1968. Adaptive significance of pigment polymorphisms in Colias butterflies. I. Variation in melanin pigment in relation to thermoregulation. Evolution 22:437-458.

Wethey, D. S. 2002. Biogeography, competition, and microclimate: the barnacle Chthamalus fragilis in New England. Integrative and Comparative Biology 42:872-880.

Zar, J. H. 1999. Biostatistical analysis. 4th ed. Prentice Hall, Englewood Cliffs, NJ.

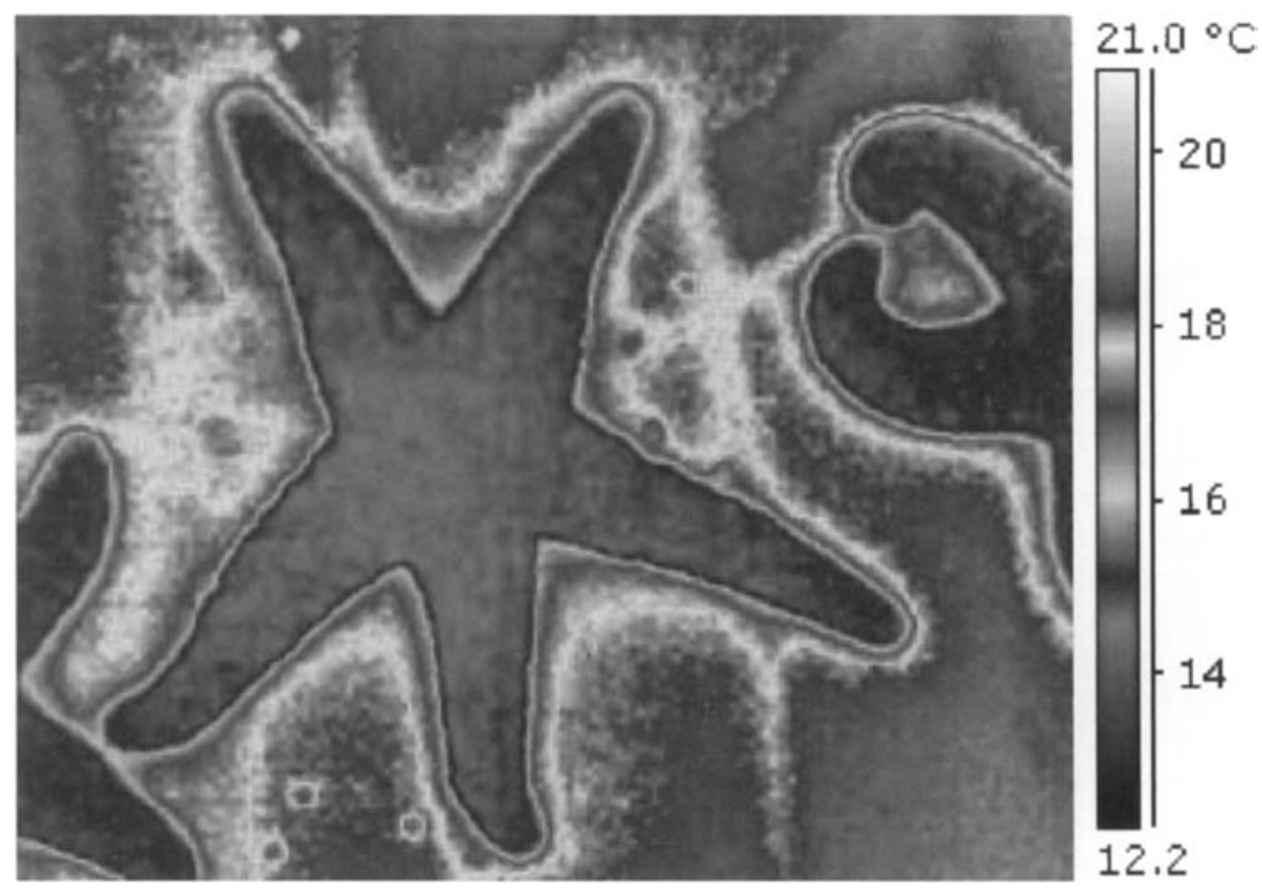

Image of sea stars taken with an infrared camera. The sea stars are cooler than their surroundings. (Photograph by Brian Helmuth and Sylvain Pincebourde.) 